\title{
Enshrining the right to live or die
}

Developments in the life sciences inevitably raise complex legal questions, such as when a human life begins and ends, and how much weight should be given to individual preferences about how and when we reproduce, or die. The law cannot avoid getting involved in these finely balanced bioethical issues, but courts and legislators are sometimes spectacularly ill-equipped to deal with them.

Take the sad case of Terri Schiavo, described in Barry Schaller's riveting book Understanding Bioethics and the Law, which describes a series of confrontations between US law and some difficult bioethical dilemmas. Eight years after Terri lost consciousness and fell into a permanent vegetative state (PVS), her husband Michael sought court authorization for the removal of Terri's feeding tube. By this time, Michael's relationship with Terri's parents, Robert and Mary Schindler, had broken down, and the Schindler family objected to the removal of the tube. Michael and the Schindlers then engaged in virtually continuous litigation for the next five years during which the tube was removed, only to be reinstated two days later. The family were joined in this unedifying legal spectacle by various religious interest groups, advocacy organizations representing people with disabilities, and by the Florida House of Representatives. With the support of governor Jeb Bush, the Florida legislature passed Terri's Law, a statute preventing the withdrawal of

Understanding Bioethics and the
Law: The Promises and Perils of the
Brave New World of Biotechnology
by Barry R. Schaller
Praeger Publishers: 2008.241 pp.
$\$ 49.95, £ 27.95$
Easeful Death: Is There a Case for
Assisted Dying?
by Mary Warnock and Elisabeth
Macdonald
Oxford University Press: 2008 .
155 pp. $\$ 26$

members and clinicians. Although there are many differences between Schaller's book and Easeful Death - Mary Warnock and Elisabeth Macdonald's elegant and thoughtful discussion of the case for assisted dying - the authors agree that private, consensual resolution of complex individual cases is almost always preferable to exposing them to the harsh glare of litigation and legislation. Warnock and Macdonald, for example, seem to regret the ending of the 'humane practice' through which people could ask their "retired medical friends" for help in storing up "a collection of drugs for future use if they found life intolerable".

The Terri Schiavo case, together with that of Dianne Pretty - a British woman with motor neurone disease who wanted to be helped to die - suggest that litigation may not resolve conflict. But at least court proceedings do focus on the individual. Schaller contrasts the US courts, which stuck to the question of whether Terri would have wanted to be kept alive in a PVS, with the "executive and legislative branches" who "disgraced themselves by pushing the boundaries of law and decency in their self-aggrandizing efforts". Although this harsh criticism seems fitting given the political exploitation of this "private ethical dilemma about a young woman's sad decline", it points to a wider problem in trying to use legislation to resolve complex bioethical issues.

nutrition and hydration from a patient "who met the unique description of Terri Schiavo". After further legal challenge, Terri's Law was eventually ruled unconstitutional by Florida's Supreme Court.

The action then shifted to the federal level, and a bill to nullify the Florida court's decision was introduced in the House of Representatives and in the Senate. President George W. Bush returned early from his holiday to sign the Senate bill at 1 a.m. on 21 March 2005. All this legislative activity did not derail the court process. The US Supreme Court refused to hear an appeal to overturn the lower court's decision that Terri's tube could be removed. Terri eventually died on 31 March 2005.

Fortunately, the Terri Schiavo case is exceptional: most end-of-life decisions are resolved privately, through discussions between family
Although the adversarial process has its disadvantages, the courts can at least attempt to deliver individualized justice, but legislation must apply to all. Translating compassionate responses to the suffering of someone such as Dianne into law is difficult precisely because legislation cannot just apply to one individual's situation: it must apply to everyone. Warnock and Macdonald quote Robin Gill, a member of the British Medical Association's medical ethics committee, who made a submission for Dianne on compassionate grounds. Her case, in Gill's view, "represented a very, very strong case indeed for voluntary euthanasia". If it was just about her, and noone else, he would be in favour of giving her access to assisted dying. But legislation cannot be personalized in this way, and Gill concluded "that more people will be made more

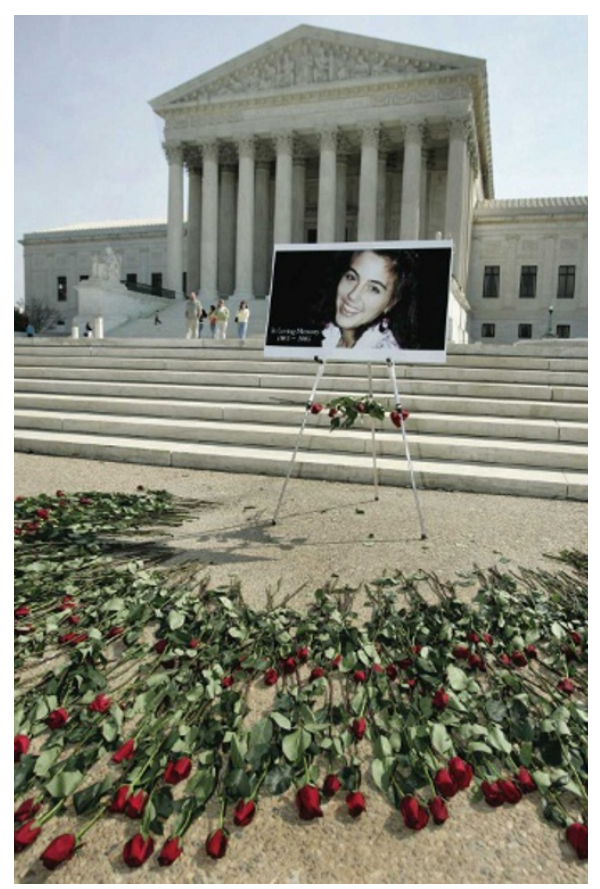

Terri Schiavo's case challenged bioethics law.

vulnerable if we change the law in favour of legalizing assisted dying".

Once an issue is before the legislature, the suffering of the individual, and the possibility of a compassionate and individualized response to that suffering, is lost. Someone such as Dianne has to die in a distressing manner, not because we think that she is vulnerable and incapable of making a considered, informed and voluntary decision to end her life, but because we think that other people might be vulnerable. Is this fair? Many would say no, and if we support Dianne's right to assisted dying, then we should not expect her to suffer for the greater good of society. Warnock and Macdonald accept that it would be hard to draft a law that would always succeed in protecting the vulnerable, but they conclude that, for compassionate reasons, we should at least try.

The legislative process offers an opportunity for special-interest groups to intervene. In the Terri Schiavo case, the concern of many advocacy groups was not the dignity and prior wishes of Terri herself, but the effect that her case might have on other people. If Terri were allowed to die, they asked, how would this affect other Americans with disabilities? These powerful advocacy groups formed an alliance with the even more powerful conservative religious lobby, leading to what Schaller describes as a "media mega-event".

The cases of Terri Schiavo and Dianne Pretty raise different issues. Terri never contemplated ending up in a PVS, and her views 
on the withdrawal of life-prolonging treatment were unknown, whereas Dianne was intelligent and competent, and had clearly articulated views on how she wanted her life to end. It is odd, perhaps, given that Terri would know nothing of the court's decision, that the outcome hinged on what her husband and parents claimed her wishes would have been, as a result of the so-called substituted judgement test. By contrast, the views of Dianne, who went on to suffer greatly before she died, were largely irrelevant and trumped by the possibility of harm to others.

The law moves in ways that are mysterious to many. Both these fascinating books, although dealing with different jurisdictions and issues, contribute to our understanding of the most important ethical challenges that lawyers will face in the coming decades.

Emily Jackson is professor of law at the London

School of Economics and Political Science,

Houghton Street, London WC2A 2AE, UK.

\section{Charting the water's edge}

Coast Lines: How Mapmakers Frame the
World and Chart Environmental Change
by Mark Monmonier
University of Chicago Press: 2008. 224 pp.
$\$ 25$

Coastal margins are drawn as precise lines on maps, yet anyone who has walked on a beach knows that coastlines are unstable. Cliffs, rocks and sands change under the influence of tides, storms, tectonic movements, global climate change and other natural and artificial phenomena.

Mark Monmonier, professor of geography at the Maxwell School of Syracuse University in New York, seeks to inform the public about how cartography and society intersect. He wishes us to look closely at maps, to recognize which features are shown or missing, and understand why. In Coast Lines, he offers an assortment of eclectic and fascinating information about how coastlines have been defined, determined and depicted, focusing on the United States in the twentieth century.

Different maps and charts of the same coastal area show different cartographic coastlines. Monmonier calls our attention to four types, explaining that each is a human construct designed to serve a specific purpose, and the result of many observations and assumptions (the latter sometimes gaining the upper hand). One cartographic coastline is the high-water line visible from offshore. Another, introduced in the nineteenth century to aid safe navigation, is the low-water line. Two are more recent: storm surge lines are designed mainly for evacuation planning and flood insurance, and inundation lines describe the plausible effects of changing geological and meteorological conditions.

Monmonier discusses the international boundaries of territorial waters. These comprise the region beyond a nation's coastline, however defined, in which that nation has sovereignty, where it can "enforce laws, levy taxes, and exclude foreign vessels not pursuing expeditious 'innocent passage' along the coast or into a port”. Under pressure from military and economic quarters, territorial waters have, in recent decades, been extended from the traditional 5.5 kilometres to 22 kilometres from shore.

Coast Lines introduces the exclusive economic zone (EEZ) in which maritime nations can "manage fisheries, mine the sea bed, and extract oil and natural gas" but cannot exclude foreign vessels. The EEZ extends 370 kilometres from shore, except where it encounters the EEZ of another nation, in which case the boundary is drawn equidistant between the two coastlines. Islands can affect where the line is drawn. For instance, because of the position of Key West and the Dry Tortuga islands off the southwestern coast of Florida, the compromise boundary between the United States and Cuba is much farther south than would be expected.

To show that "good cartography is seldom cheap and rarely happens overnight", Monmonier tells the story of the ambitious International Map of the World project. Following a German geographer's proposal at an international conference in 1891, cartographers from the industrialized nations agreed to produce a series of maps with uniform projection, symbols, style, scale and technique, which would adequately describe all of the mountains, rivers and key coastal features of the world. When complete, the mosaic of assembled 'millionth maps' drawn to a scale of 1:1,000,000 — would have covered more than 185 square metres (half the size of a basketball court) at a cost of $£ 100,000$ (US\$200,000), a significant sum at the time. Some maps were eventually produced but, with most nations reluctant to pay their share and with two intervening world wars, this grand project ended in a whimper in the second half of the twentieth century.

The failure of the International Map of the World project can, to some extent, be explained by emerging technologies that made the old standards obsolete. Some advances have revolutionized data collection and display, and some (such as intercontinental ballistic missiles) expanded the military's need for maps that were increasingly accurate and sophisticated. Monmonier has good knowledge of cartographic technologies. In a section on overhead imaging, he introduces the problem of consolidating images taken from different angles and discusses techniques for remote sensing. In another chapter he surveys the types of electronic chart that are now available.

Today, the mapping of coastlines has environmental and political implications. Proposing that cartographers can document global climate

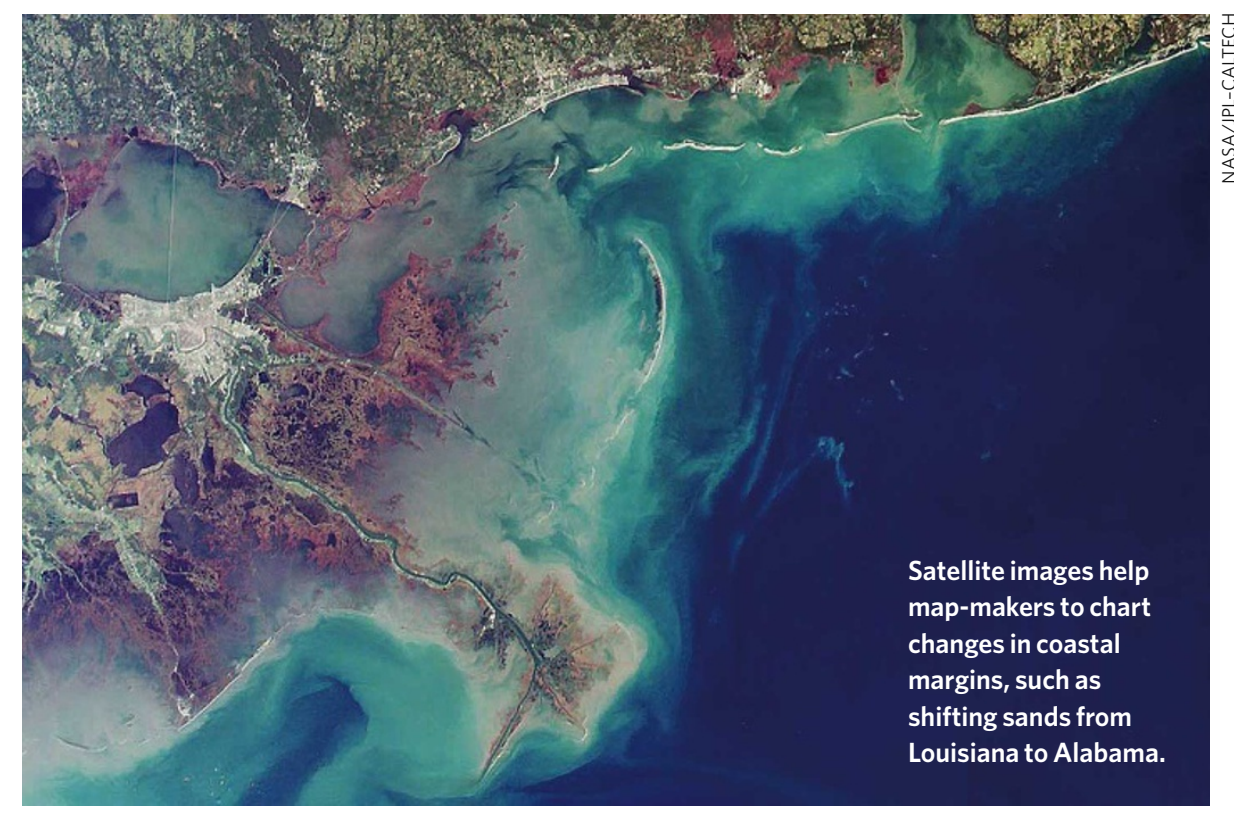

